Development of the Low-Pressure Hydride/Dehydride Process 
An Affirmative Action/Equal Opportunity Employer

This report was prepared as an account of work sponsored by an agency of the United States Government. Neither The Regents of the University of California, the United States

Government nor any agency thereof, nor any of their employees, makes any warranty, express or implied, or assumes any legal liability or responsibility for the accuracy, completeness, or usefulness of any information, apparatus, product, or process disclosed, or represents that its use would not infringe privately owned rights. Reference herein to any specific commercial product, process, or service by trade name, trademark, manufacturer, or otherwise, does not necessarily constitute or imply its endorsement, recommendation, or favoring by The Regents of the University of California, the United States Government, or any agency thereof. The views and opinions of authors expressed herein do not necessarily state or reflect those of The Regents of the University of California, the United States Government, or any agency thereof. Los Alamos National Laboratory strongly supports academic freedom and a researcher's right to publish; as an institution, however, the Laboratory does not endorse the viewopoint of a publication or guarantee its technical correctness. 
Development of the Low-Pressure

Hydride/Dehydride Process

Rueben L. Gutierrez*

*Project Leader for UK, Weapon Material Experiments,

Nuclear Materials and Technology Division

\section{Los Alamos}




\section{Table of Contents}

Development of the Low-Pressure Hydride/Dehydride Process .................................... 1

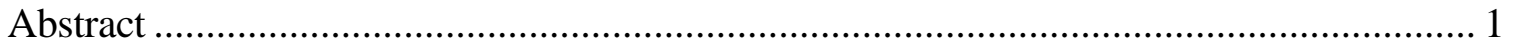

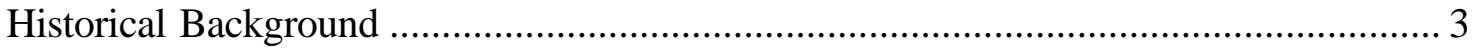

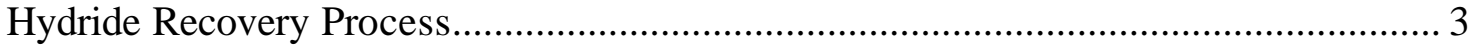

Development of Low-Pressure Hydride Process at Los Alamos.................................. 4

Development of Single-Chamber Hydride Recovery System ................................... 5

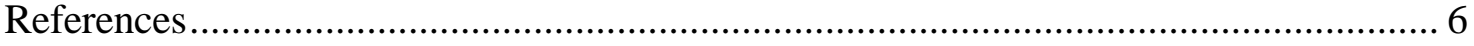




\title{
Development of the Low-Pressure Hydride/Dehydride Process
}

by

Rueben L. Gutierrez

\begin{abstract}
The low-pressure hydride/dehydride process was developed from the need to recover thin-film coatings of plutonium metal from the inner walls of an isotope separation chamber located at Los Alamos and to improve the safety operation of a hydride recovery process using hydrogen at a pressure of $0.7 \mathrm{~atm}$ at Rocky Flats. This process is now the heart of the Advanced Recovery and Integrated Extraction System (ARIES) project.
\end{abstract}




\section{Historical Background}

In March of 1982, Los Alamos engaged in a joint program with TRW to demonstrate the possible use of an isotope separation process that had been developed by TRW. This Plasma Separation Process used a technique (for which TRW had obtained a patent) of generating a metal plasma and by using a tuned magnetic field could separate isotopes of that element while in the plasma phase.

Members of the Los Alamos team came from two different divisions:

- from MST-13, Rueben L. Gutierrez (project leader), William Olson, Jim Andrew, and Calvin Klatt;

- from CTR-9, David Weldon and John Wollan.

This joint project established the capability of casting plutonium metal onto a 9-inch diameter tantalum plate, which was cooled with circulating water on the back side to sputter the plutonium metal into an area where it would be excited into a metal plasma and by use of the ion cyclotron resonance principle, isotopes of formed ions can be separated. The plutonium plasma was then studied by the use of Langmuir and ion probes. The entire process was conducted inside a 5-foot-long by 12 -inch-diameter stainless-steel chamber, which was surrounded on the outside by eight equally spaced 3 -foot-diameter water-cooled copper pancake coils used for generating the magnetic field within the plasma chamber.

On July 11, 1983, the joint Los Alamos/TRW team produced the first plutonium metal plasma at the Los Alamos TA-55 Plutonium Facility. As studies progressed during the next 12 months, we thought of how thin-film coatings of plutonium metal would be recovered from the vessel's internal walls. This thin-film plutonium coating came from plutonium ions that strayed from the plasma and plated onto the vessel walls. The bulk of the plutonium ions plated onto a receptor plate at the opposite end of the chamber.

\section{Hydride Recovery Process}

The primary reason for recovering the plutonium metal was to avert any worry about a plutonium buildup that would lead to criticality issues. Gutierrez settled on using the hydride process for recovering the plated plutonium metal from the inner surface of the chamber vessel. During 1982, Gutierrez interacted with Bob DeGrazio and Art Dye from Rocky Flats. They were in charge of the plutonium hydride process that was used to recover plutonium metal from sputter targets, casting molds, and substrates to which it was bonded.

The process that was used at Rocky Flats was to fill a chamber that contained the substrate with hydrogen gas to a pressure of approximately 500 Torr $(\sim 0.7 \mathrm{~atm})$. Plutonium metal was recovered from the surfaces of sputter targets, casting molds, and bonded pits. Approximately $98 \%$ of the plutonium was recovered from the substrates, and the remaining material was recovered by brushing the areas still containing 
plutonium with sulfamic acid, which generated small volumes of contaminated acid. The hydride process eliminated the large volumes of contaminated acid that were being generated by a parallel acid recovery process that was being used to recover plutonium from the same type of substrates. DeGrazio consulted with Gutierrez in the hopes that he could assist Rocky Flats in modifying their hydriding process. DeGrazio's concern was that Rocky Flats management was considering a shut down of the hydride process. Management felt that there was an element of high risk because of the use of hydrogen gas at high pressure.

\section{Development of Low-Pressure Hydride Process at Los Alamos}

By 1984, the isotope separation programs being conducted for the DOE were being placed on a slow-down process, with funding cut for the Plasma Separation Process, causing a shut down of the program. The laser isotope programs continued for five more years before being shut down. Even though the need to develop the hydride process for the Plasma Separation Process was removed, the process had appeal because of its simple use in removing plutonium metal from substrate surfaces. Until the development of the hydride process, plutonium metal was removed from the substrates by either machining or dissolving the plutonium off of the substrate in acid solution, a process that generated large volumes of contaminated acid.

DeGrazio indicated that the hydride process would not work on certain substrates if the pressure were reduced much below the 500-Torr level being used by Rocky Flats. Plutonium metal will form an oxide surface when exposed to moisture and air and form a protective coating around the plutonium metal. If the oxide coating was thick, it either retarded the reaction or prevented the low-pressure hydrogen to form a metal hydride. During Gutierrez's graduate studies related to plasma chemistry, he had developed a technique for using a dc discharge to generate a hydrogen plasma into which organic compounds were injected. These studies initiated reactions within a hydrogen plasma and he observed the formation of different compounds and the types of bonds formed in the new compounds. All this was done in a low-pressure hydrogen plasma of approximately $1 \times 10^{-2}$ Torr.

It occurred to Gutierrez that if a low-pressure hydrogen plasma could be generated over the oxide surface covering the plutonium, the energetic hydrogen plasma would break down any oxide surface, regardless of thickness, after a short period of time. At a certain point in the process, the hydrogen plasma would be shut down and the pure hydrogen gas would react with the exposed plutonium surface to form plutonium hydride powder, even though the hydrogen pressure was low.

To prove this process, Gutierrez initiated the construction of a stainless-steel reaction vessel for generating a low-pressure hydrogen plasma. Gutierrez recruited Hans-Joerg Meyer-Christians from MST-7 to assist with the electronics related to the dc discharge process. Wally Anderson, MST-13, was assigned the task of designing a gas-control system to flow hydrogen gas at low pressure into and out of the reaction vessel. Bart Flamm was the technician who helped with the glovebox setup of all experiments. As 
the studies of low-pressure hydriding in a plasma environment progressed, we were elated that the supposition that the hydrogen plasma would break down the oxide layer and allow hydriding of the plutonium surface to occur was proven. Because of our success, we were encouraged by the Laboratory's Patent Office to submit an Invention Disclosure, DOE Case No. S-68, 004. The Laboratory filed this disclosure on April 20, 1990. As we continued our studies, we determined that by thermal heating the surface of the part, we were able to initiate plutonium hydriding regardless of how much of an oxide coating was on the plutonium metal.

Thermal heating was being used by Rocky Flats, and they indicated to us that the process was not effective unless the hydrogen pressure remained above 500 Torr. This information moved us toward the use of a low-pressure hydrogen plasma. Later studies showed that when substrates hold sufficient mass of plutonium metal, thermal heating initiates hydriding at almost any pressure of hydrogen gas, and the reaction is rapid. However, when substrates hold small amounts of plutonium metal, in the form of thinfilm coatings on their surfaces, the hydride reaction is extremely slow and gives the impression that the reaction is not occurring. Therefore, when Rocky Flats was trying to recover plutonium metal from sputter shields or from the surfaces of casting molds, the mass of plutonium metal was not very large. They had surmised that for any amount of plutonium metal, a certain minimum hydrogen pressure was required to initiate the hydriding process.

\section{Development of Single-Chamber Hydride Recovery System}

At Rocky Flats, recovery of plutonium metal using the hydride process was a two-step process. The hydride step was conducted in a chamber located inside an inert gas glovebox. The inert gas was nitrogen that contained a maximum content of 5\% oxygen. The low oxygen content is required because plutonium hydride powder will instantaneously ignite upon contact with significant levels of oxygen. The hydride powder was moved from the hydriding glovebox into another inert glovebox that contained a furnace that was used to heat the hydride powder in the presence of air and to convert the plutonium hydride to plutonium oxide. When the plutonium was converted to the oxide form, the material could be handled in air gloveboxes, and the fire hazard concern was eliminated.

At Los Alamos, we were using the same two-step process at first. Then, at a plutonium R\&D section meeting in 1988, Meyer-Christians proposed the use of a single-chamber recovery process. His suggestion was to build a chamber in a specific shape to hold the part to be hydrided at the top. A fixed volume of hydrogen gas would be flowed into the chamber to start the hydride process. The small plutonium hydride particles would then fall from the part and flow down the chamber walls into a crucible located at the bottom of the chamber.

The heated crucible would collect the plutonium hydride particles, drive off the hydrogen, and leave plutonium metal particles. The hydrogen gas would migrate to the top of the chamber and continue with the hydride process. In the meantime, the 
heated plutonium metal particles would combine into a molten mass inside the heated crucible. When the hydrogen pressure in the chamber stabilized at the original level first injected into the chamber, the hydride recovery reaction was complete. The hydrogen gas was then pumped out of the chamber and stored. The crucible heating system was turned off, and what remained after the chamber cooled was plutonium metal in the form of a hockey puck.

Meyer-Christians' concept was brilliant and saved several processing steps by eliminating the need to convert from hydride to oxide and then oxide to metal. John Haschke, John Ward, Bart Flamm, Garlan Isom, and Joe Martz (all from MST-13) assisted with the final design and engineering details, and brought the process into successful operation. It should be noted that in mid-1989, TA-55 was reorganized as a new division (Nuclear Materials Technology) and MST-13 became NMT-5.

What started out as a technique being developed to recover thin-film coatings of plutonium metal and to operate the hydriding process in a safe manner evolved into an integrated process for recovering plutonium metal from pits. This single-chamber hydride recovery process is now the heart of the Advanced Recovery and Integrated Extraction System (ARIES) project, which recovers plutonium from weapons being retired from the U.S. nuclear stockpile.

In 1995, this process was nominated by the Laboratory and received the R\&D 100 Award from R\&D Magazine. Unfortunately, our dear friend and colleague, Meyer-Christians was stricken with cancer in late 1989 and passed away April 17, 1991. We knew him as Hanno and we deeply regret that Hanno did not live to be present at the award ceremony.

\section{References}

1. R. L. Gutierrez, et al., Plutonium Source Experiment, Los Alamos National Laboratory report LA-10407-MS, 1985.

2. R. L. Gutierrez and S. D. Soderquist, Plutonium Source Plate Fabrication, Los Alamos National Laboratory report LA-11302-MS, June 1988.

3. Industrial Research \& Development magazine, "Isotope Separation Achieved Through Plutonium Plasma," pp. 63-64, October 1983.

4. R. P. DeGrazio, Prototype Hydriding Apparatus, Dow Chemical Rocky Flats Plant report RFP-2340, March 1975.

5. R. L. Gutierrez, et al., Material and Fabrication (CM) Annual Report, Los Alamos National Laboratory report LA-10405-PR, May 1985.

6. R. L. Gutierrez, et al., Material and Fabrication (CM) Annual Report, Los Alamos National Laboratory report LA-10832-PR, February 1987.

7. R. L. Gutierrez, et al., Plasma Hydriding, Los Alamos National Laboratory report LA-11255, May 1988.

8. B. H. Cotrell, Plasma Hydride Process, Disclosure of Invention, Los Alamos National Laboratory letter, LC/IP: 90-181, April 20, 1990. 
This report has been reproduced directly from the best available copy. It is available electronically on the Web (http://www.doe.gov/bridge).

Copies are available for sale to U.S. Department of Energy employees and contractors from-

Office of Scientific and Technical Information

P.O. Box 62

Oak Ridge, TN 37831

(423) 576-8401

Copies are available for sale to the public from-

National Technical Information Service

U.S. Department of Commerce

5285 Port Royal Road

Springfield, VA 22616

(800) 553-6847 


\section{Los Alamos \\ NATIONAL LABORATORY \\ Los Alamos, New Mexico 87545}

